\title{
Experimental and Theoretical Studies on the Effect of Die Temperature on the Quality of the Products in High-Pressure Die-Casting Process
}

\author{
Mohammad Sadeghi and Jafar Mahmoudi \\ HST Department, MÄlardalen University, P.O. Box 883, 721 23, Västerås, Sweden \\ Correspondence should be addressed to Mohammad Sadeghi, mohammad.sadeghi@mdh.se
}

Received 9 April 2012; Revised 30 May 2012; Accepted 20 June 2012

Academic Editor: Rui Vilar

Copyright (C) 2012 M. Sadeghi and J. Mahmoudi. This is an open access article distributed under the Creative Commons Attribution License, which permits unrestricted use, distribution, and reproduction in any medium, provided the original work is properly cited.

\begin{abstract}
Die temperature in high-pressure die casting of A380 alloy is optimized by experimental observation and numerical simulation. Ladder frame (one part of the new motor EF7) with a very complicated geometry was chosen as an experimental sample. Die temperature and melt temperature were examined to produce a sound part. Die temperatures at the initial step and the final filling positions were measured and the difference between these values was calculated. ProCAST software was used to simulate the fluid flow and solidification step of the part, and the results were verified by experimental measurements. It is shown that the proper die temperature for this alloy is above $200^{\circ} \mathrm{C}$.
\end{abstract}

\section{Introduction}

High-pressure die-casting (HPDC) process has been widely used to manufacture a large variety of products with high dimensional accuracy and productivities. It has a much faster production rate in comparison to other methods and it is an economical and efficient method for producing components with low surface roughness and high-dimensional accuracy. All major aluminum automotive components can be processed with this technology [1-7]. In this process, the metal is injected into the die at high speeds $(30-100 \mathrm{~m} / \mathrm{s}$ and typically $40-60 \mathrm{~m} / \mathrm{s}$ for aluminum alloys [2]) and under high pressure through complex gate and runner systems [3].

Although HPDC has a considerably higher speed than other metal forming processes, due to complexity of the process and the number of variables, optimization of the process is essential. In particular, there are issues related to control of die temperature, solidification of the components, quality control of the castings, and more important, development or use of a coherent and integrated system. The mechanical properties of a die-cast product are principally related to the die temperature, the metal velocity at the gate, and the applied casting pressure [4].
Combination of die temperature, fluidity of the molten metal, geometrical complexity of the parts, and cooling rate during die casting affect the integrity of a cast component. If these parameters are not adequately controlled, various defects within the finished component will be expected $[6,7]$. Thermal profile of the die during operation is another important factor in the production of high-quality components. Too high temperature of the die will lead to longer solidification which consequently prolongs the cycle time, while a cold die will contribute to a number of surface defects $[3,8,9]$.

Kermanpur et al. [10] used FLOW-3D software to simulate the filling and solidification sequences of two automotive components. They process the appropriateness of the running and feeding systems. Schneiderbauer et al. [11] investigated the flow of molten metal in the die cavity threefoldly: (a) analytically, (b) experimentally, and (c) numerically. They studied the effect of flow condition on casting defects. Pereira et al. [12] used ProCAST software to simulate HPDC process. They studied the effect of the die temperature and melt temperature die life. Rai et al. [13] worked on optimization of main process parameters in HPDC, namely, die temperature, melt temperature, and plunger velocity. 
TABLe 1: Material properties.

\begin{tabular}{lc}
\hline Solidus temperature & $595\left[{ }^{\circ} \mathrm{C}\right]$ \\
Liquidus temperature & $521\left[{ }^{\circ} \mathrm{C}\right]$ \\
Specific heat & $1.13044[\mathrm{~kJ} / \mathrm{kg} / \mathrm{K}]$ \\
Density & $2480\left[\mathrm{~kg} / \mathrm{m}^{3}\right]$ \\
Conductivity & $100.4832[\mathrm{~W} / \mathrm{m} / \mathrm{K}]$ \\
Latent heat & $218.644[\mathrm{~kJ} / \mathrm{kg}]$ \\
Solid fraction & According to Scheil equation \\
\hline
\end{tabular}

TABLE 2: Initial and boundary conditions.
Ram velocity

Die temperature

Melt temperature

Heat transfer coefficient

Number of finite element meshes
$2-4 \mathrm{~m} / \mathrm{s}$

$150,200 \& 250^{\circ} \mathrm{C}$

$670,680,690^{\circ} \mathrm{C}$

$9000 \mathrm{w} / \mathrm{m}^{2} \cdot \mathrm{K}[17]$ 521380
Some other investigators have also worked on optimization of process parameters on die-casting by simulation [1416]. However in many of these works, the geometry of the part is simple and there are few researches on very complex part in industry. The aim of this work is optimization of process parameters in die casting of a complex automotive component named ladder frame by simulation.

\section{Governing Equations}

In order to perform the mould filling and solidification simulation of automotive part, the commercial finite element code ProCAST was used. Within the framework of an Euclidian description, this software is capable of solving simultaneously three-dimensional transient thermal and fluid flow problems with free surface. The set of partial differential equations to be solved is briefly summarized below.

Mass Balance. One has

$$
\frac{\partial}{\partial t} \rho+\operatorname{div}(\rho v)=0
$$

where $\rho\left(\mathrm{N} / \mathrm{m}^{2}\right)$ and $v(\mathrm{~m} / \mathrm{s})$ are the volumetric mass and the velocity of the fluid, respectively.

Momentum Balance. One has

$$
\frac{\partial}{\partial t}(\rho v)+\operatorname{div}(\rho v \otimes v)=-\operatorname{grad}(p)+\operatorname{div} \sigma^{v}+\rho g,
$$

where $g\left(\mathrm{~m} / \mathrm{s}^{2}\right)$ is the gravitation vector, $p\left(\mathrm{~N} / \mathrm{m}^{2}\right)$ is the fluid pressure, and $\sigma^{v}$ is the viscous stress tensor.

Energy Balance, Written as an Enthalpy Formulation. One has

$$
\frac{\partial}{\partial t}(\rho h)+\operatorname{div}(\rho h v)=\operatorname{div}(k \cdot \operatorname{grad} T)+Q_{\text {mech }}
$$

In this equation, $Q_{\text {mech }}(J)$ is a volumetric heat source that account for mechanically induced dissipation effects, $T$ is the temperature, $k$ is the thermal conductivity of the medium, and $h$ is its specific enthalpy. Please note that the entire enthalpy is transported with the velocity of the fluid.

In order to account for solidification, $\rho h$ is written as follows:

$$
\rho h=\int_{0}^{T} \rho c_{p}(\theta) d \theta+\rho L\left(1-f_{s}\right)
$$

where $c_{p}$ and $L$ are the specific heat and latent heat of fusion, respectively, and $f_{s}$ is the volume fraction of the solid.

Free surface modeling is achieved with a scalar variable, $\Phi$, describing the local volume fraction of the fluid (i.e., $\Phi$ $=0 / 1$ if the "point" is empty/full of SSM). Previous balance equations are averaged with this variable, which is adverted according to:

$$
\frac{\partial}{\partial t} \Phi+v \cdot \operatorname{grad} \Phi=0
$$

These equations need to be explained in the frame work of the paper.

\section{Modeling Procedure}

A 3-dimensional model of the cast product is an important input for design and analysis functions in ProCAST and can be imported through a data exchange interface using the industry standard Parasolid format (Figure 1). The material properties of the alloy were extracted from the software database and are shown in Table 1.

In order to evaluate the effect of process parameters on the filling pattern and quality of the final product, three main process parameters were varied during simulation and their effects on the results were studied. Initial and boundary conditions used in the simulation are given in Table 2. To ensure mesh independency of the results, two deferent mesh sizes were used and simulation results were compared at these two mesh sizes.

\section{Experimental Procedures}

The material used in this study was A380 material. Die temperatures were $150^{\circ} \mathrm{C}, 200^{\circ} \mathrm{C}$, and $250^{\circ} \mathrm{C}$. Initial melt temperature of $680^{\circ} \mathrm{C}$, shot sleeve speed of $3 \mathrm{~m} / \mathrm{s}$, and speed melt in gate of $55 \mathrm{~m} / \mathrm{s}$ for the ladder frame were assumed. Measurement of the melt temperature was carried out by thermocouple and Laser pyrometer (model chy 110) at the die surface.

Melt temperature was measured at the die entrance at the start of injection and at the end of filling. This test was done at the various die temperatures. The IDRA1600 die-cast machine was used for injection. Test results are illustrated in Table 3 and Figures 2-4.

The variations of melt temperature versus die temperature in different cases are shown in Figure 2. The results show that the die temperature varies from 150 to $250^{\circ} \mathrm{C}$, while the melt temperature varies between $660^{\circ} \mathrm{C}$ and $680^{\circ} \mathrm{C}$. 


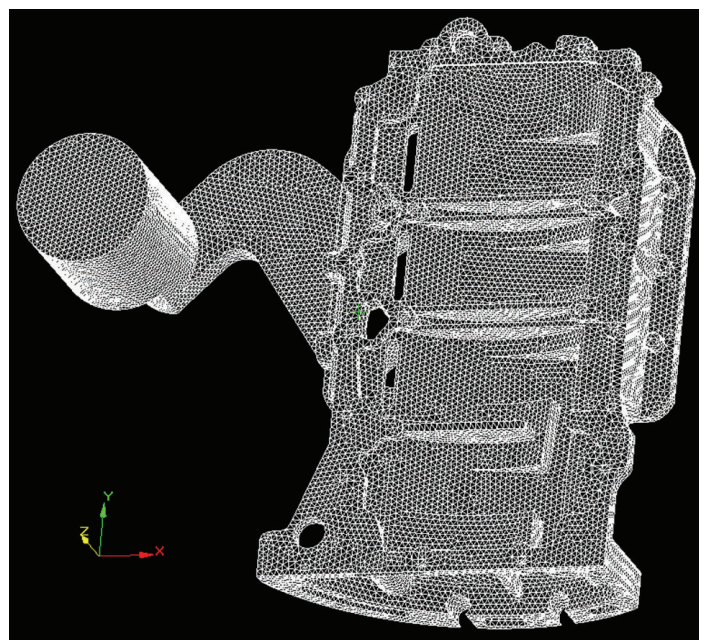

FIGURE 1: Geometry of ladder frame product.

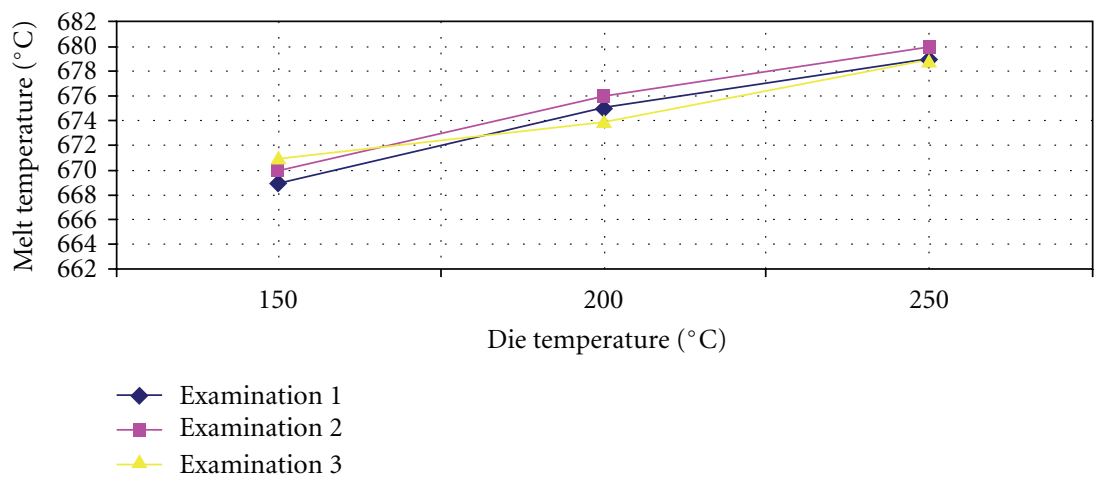

FIGURE 2: Melt temperatures at die entrance and start injection versus die temperatures.

TABLE 3: Melt temperature at outset injection in shot sleeve and at end injection final filling position.

\begin{tabular}{lcc}
\hline Die temperature ${ }^{\circ} \mathrm{C}$ & Melt temperature ${ }^{\circ} \mathrm{C}$ at outset injection & Melt temperature ${ }^{\circ} \mathrm{C}$ at end injection \\
\hline 150 & $670,669,671$ & $650,649,652$ \\
200 & $675,676,674$ & $664,666,663$ \\
250 & $679,680,679$ & $671,670,668$ \\
\hline
\end{tabular}

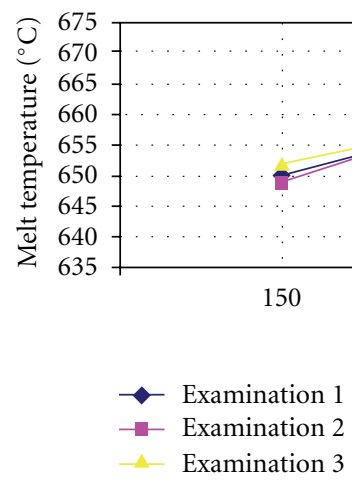

FIgURE 3: Melt temperatures at the end of the die and end injection versus die temperatures. 


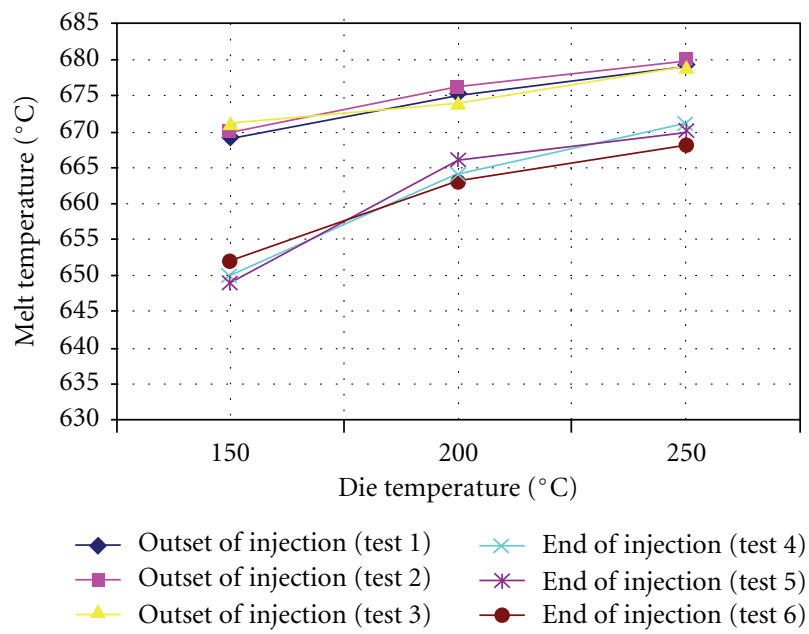

FIGURE 4: Reduction of melt temperature at various die temperatures at the initial and the end of injection.
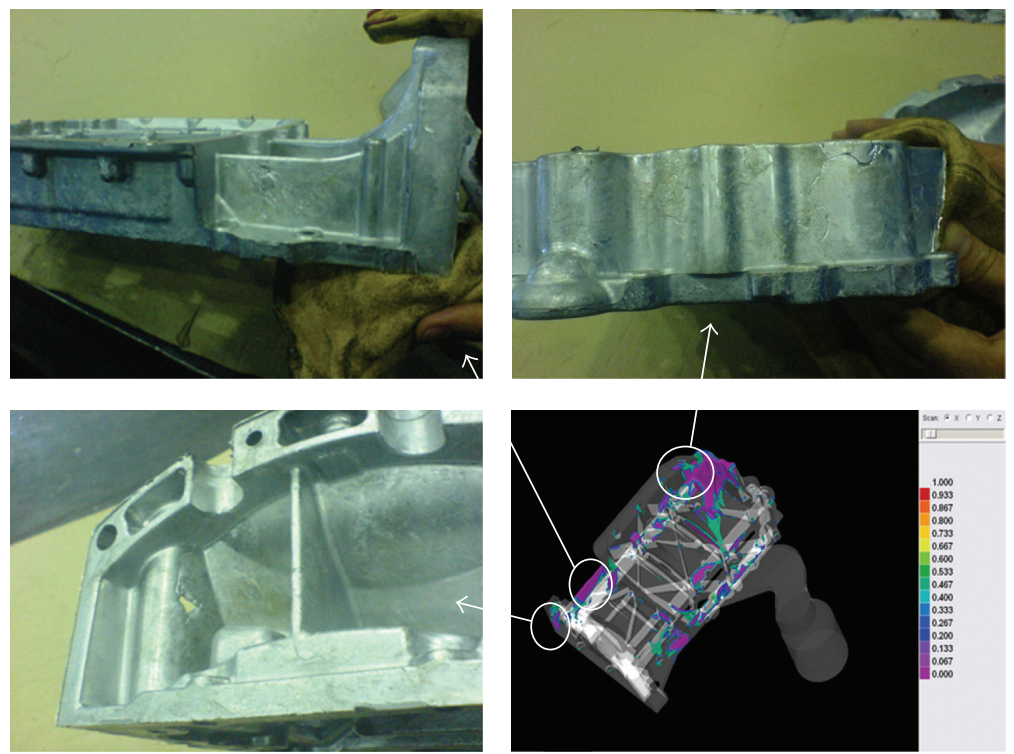

FIGURE 5: Cold flow surface defects at final filling positions.

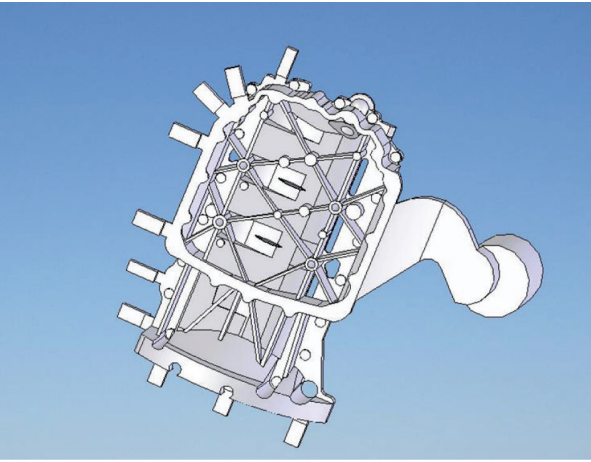

FIGURE 6: positions of added overflows to the mold. 


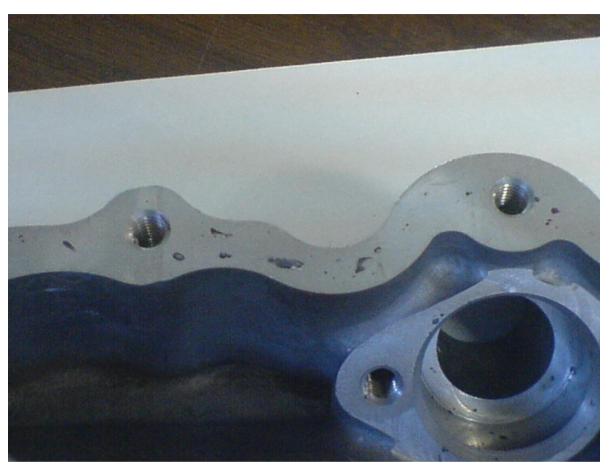

(a)

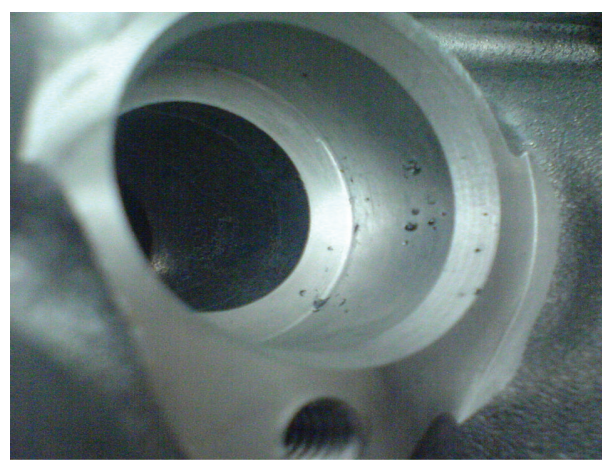

(b)

Figure 7: Some porosity defects.
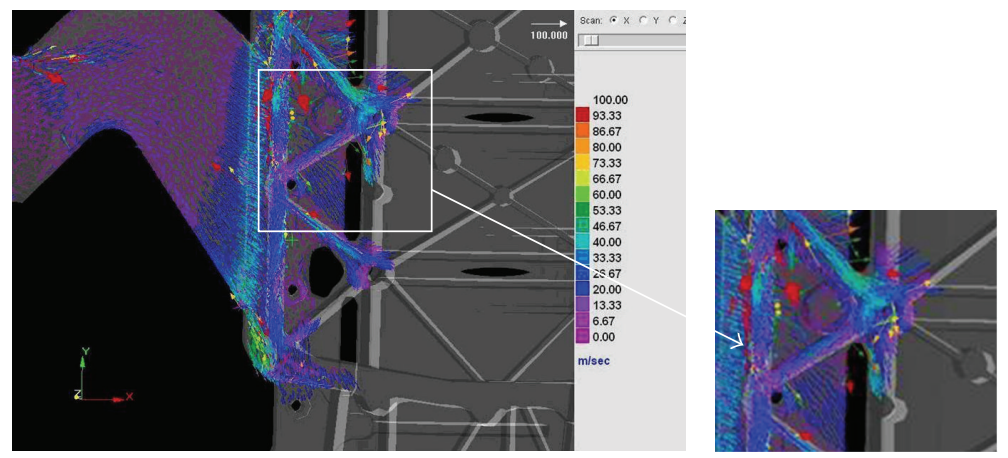

(a)
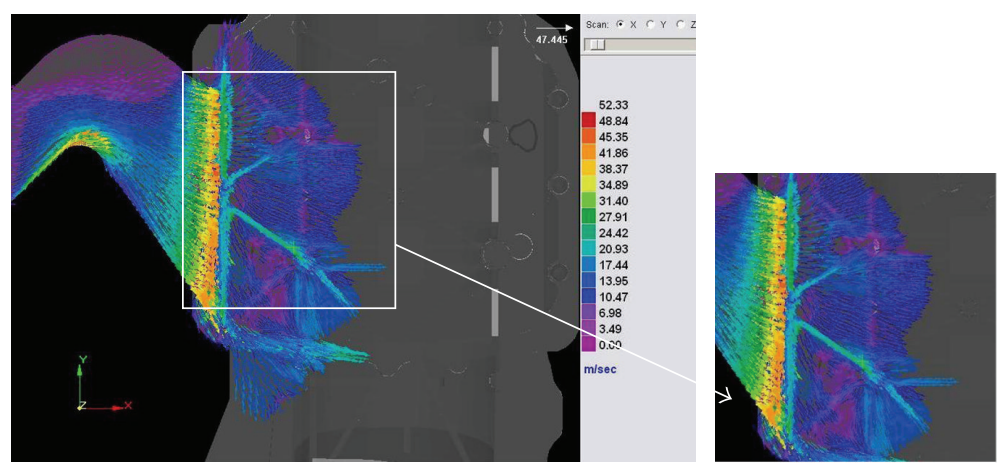

(b)

FIGURE 8: Velocity vectors of the melt at the three holes in the front of the gate.

Figure 5 shows typical examples of cold flow surface defects in pieces produced in a die with temperature of $150^{\circ} \mathrm{C}$ (Figures 1-3). As can be seen from this figure, cold shot defects occur at final filling positions predicted by the software.

This kind of defect occurs because the melt has to move a long way in the die cavity and finally it reaches its liquidus temperature. If the metal is partially solidified when two flows come together, the laps are formed and laminations, as the characteristic of surface defects, appear. This defect is often apparent at the end of the flow pattern especially when the die is colder. Overflows were added in these positions to eliminate these kinds of defects (Figure 6).

Gas porosities caused by entrapped air during metal injection are illustrated in Figure 7. Porosity caused by turbulent flow, low die temperature, and long flow path in combination with a thin wall section. An example of turbulent flow pattern of the melt at three holes in front of the gate is shown in Figure 8(a). These holes cause agitation in the flow pattern. This agitation can result in air entrapment and oxidation and also they can change the flow pattern of the molten metal to a more turbulent one and cause branch-like flow. 


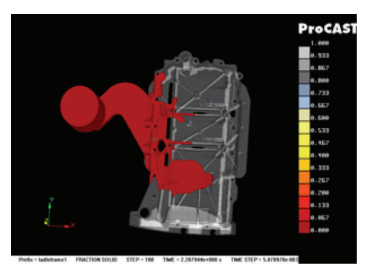

(a)

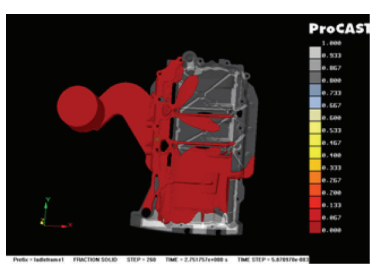

(b)

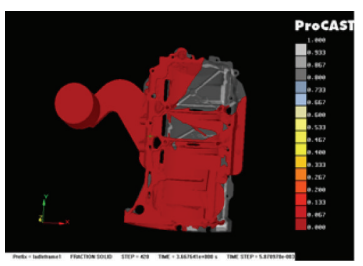

(c)

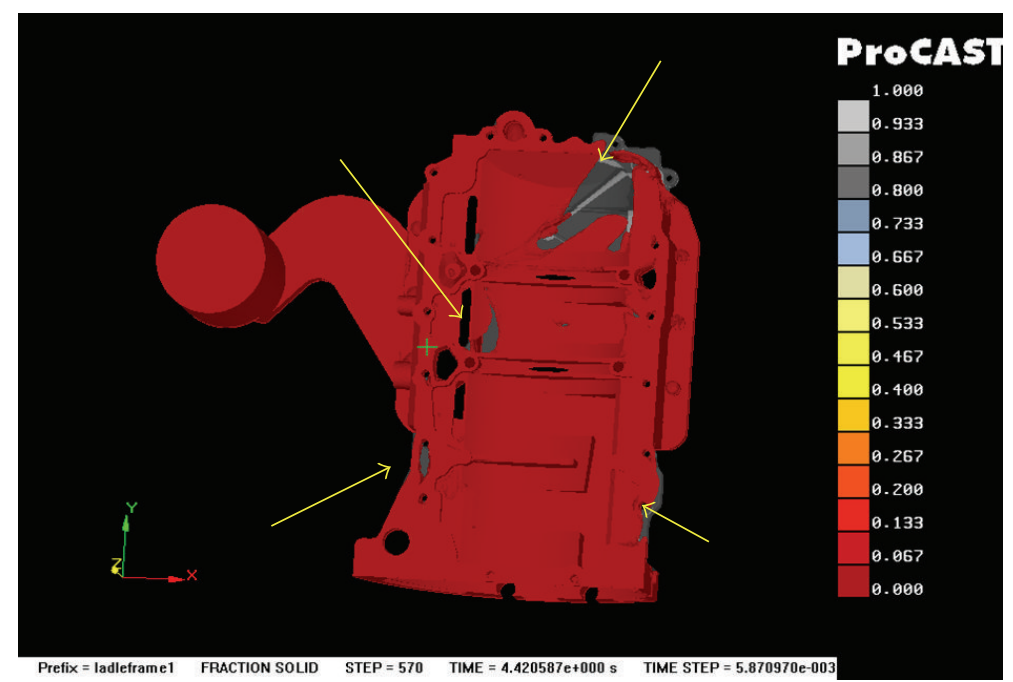

(d)

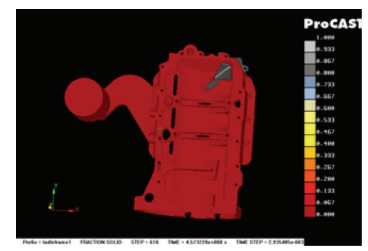

(e)

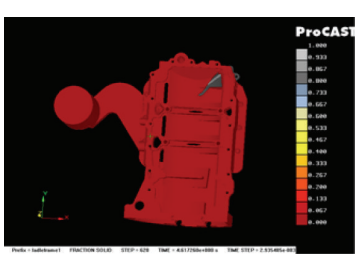

(f)

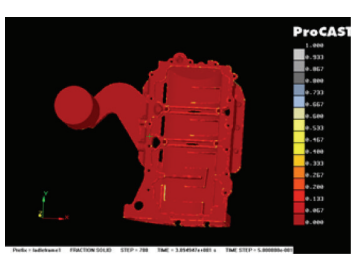

(g)

Figure 9: Steps filled die by the melt and show End points.

By eliminating these three holes in the model (Figure 8(b)), more stable flow pattern was observed. Some other possible sites of air entrapment are shown in Figure 9(d). These sites have been generated as a result of complex and branch-like flow pattern in the mold.

Simulations Results. The boundary conditions implemented in the software are shown in Table 2. Then, the model was run for die temperatures of $150^{\circ} \mathrm{C}, 200^{\circ} \mathrm{C}$, and $250^{\circ} \mathrm{C}$ while other parameters kept constant. The flow pattern of the melt in the die at $200^{\circ} \mathrm{C}$ is shown in Figure 9.

Temperature distribution of the melt in two different die temperatures at equal time is compared in Figure 10. In the case of $150^{\circ} \mathrm{C}$ die temperature, melt temperature falls down near the liquidus temperature of the material and there is danger of cold shot flow in this case.

Figure 11 shows the final solidification positions at the end of casting. Shrinkage defects occurred at the final solidification positions are shown in Figure 12. In this figure, one can see a comparison between simulation results and experimental observation at those areas. The outer side of the part has shrinkage defects which were predicted by the software. The verified model interestingly represented the correct location of the porosity defects in the castings.

\section{Discussion}

The difference of two melt temperature curves at the initial and end of the process at $250^{\circ} \mathrm{C}, 200^{\circ} \mathrm{C}$, and $150^{\circ} \mathrm{C}$ are $9.5^{\circ} \mathrm{C}, 10^{\circ} \mathrm{C}$, and $19.5^{\circ} \mathrm{C}$, respectively (Figure 3 ). It is seen that there is a break point in the curve of end injection at die temperature of $200^{\circ} \mathrm{C}$. Therefore, defects are more probable at die temperatures less than $200^{\circ} \mathrm{C}$. These results are supported by experimental observations. With regard to this break point, it can be seen that the normal die temperature for this alloy is $200^{\circ} \mathrm{C}$. Maximum temperature depends on the die cooling system and optimized cycle time for production of a specific part.

Filling pattern of the melt is shown in Figure 6. Final filling positions in the die are illustrated in this figure. Same 


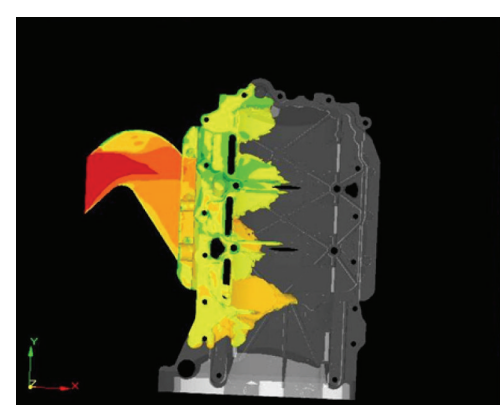

(a1)

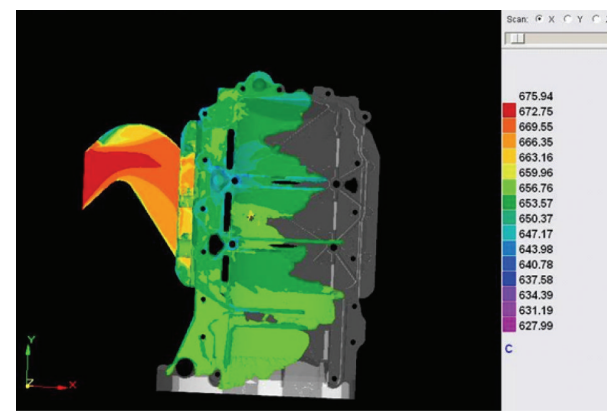

(a2)

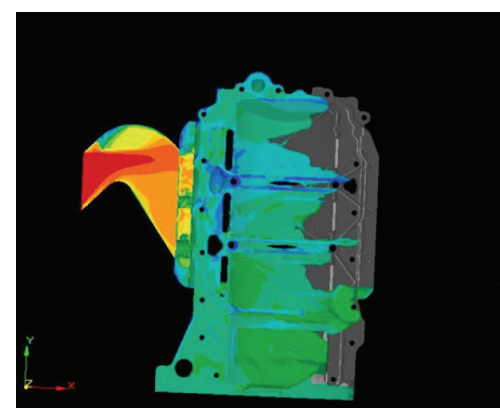

(a3)

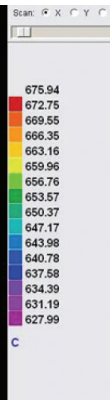

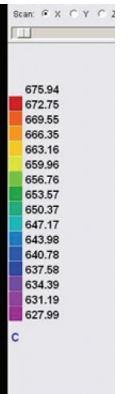

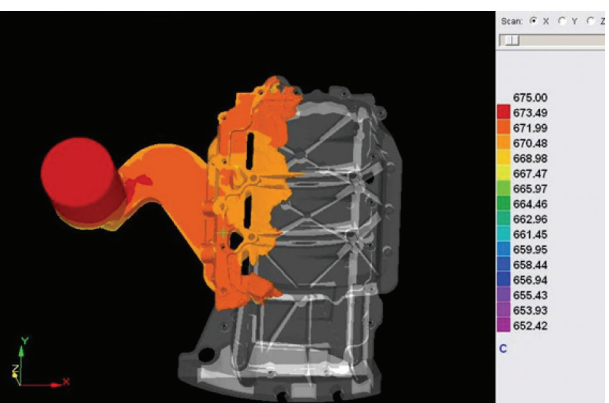

(b1)

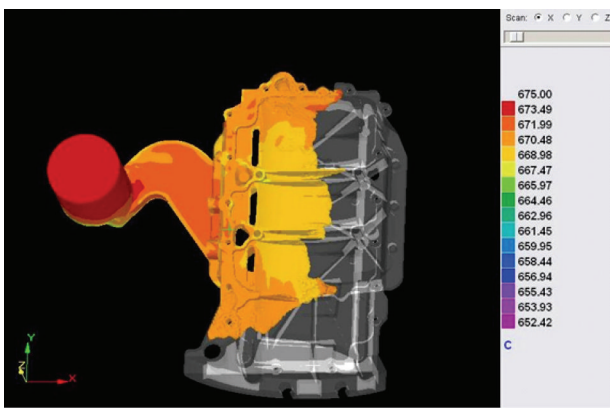

(b2)

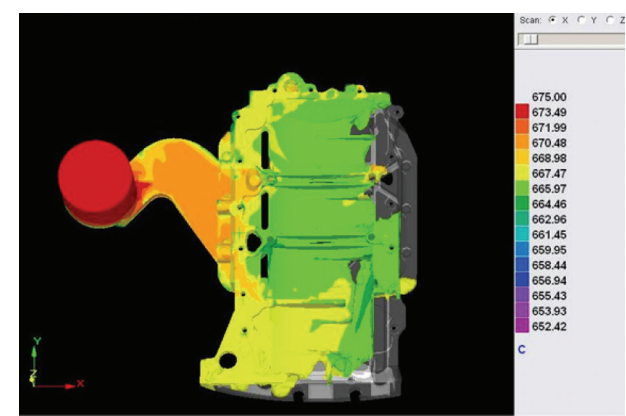

(b3)

FIGURE 10: Flow pattern of melt with die temperature (a) $150^{\circ} \mathrm{C}$ and (b) $250^{\circ} \mathrm{C}$ in same time. Time a1 $=\mathrm{b} 1, \mathrm{a} 2=\mathrm{b} 2, \mathrm{and} \mathrm{a} 3=\mathrm{b} 3$.

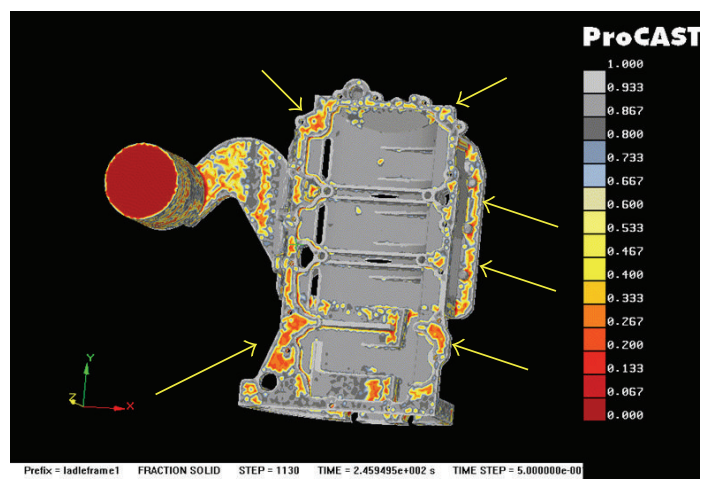

FIGURE 11: Hot spots at the end of solidification step, which are susceptible to casting defects.

thing was observed at the die temperature of $150^{\circ} \mathrm{C}$ (Figures 1-3). Filled Percentages of mold at two die temperatures of $150^{\circ} \mathrm{C}$ and $250^{\circ} \mathrm{C}$ are shown in Figure 5. By comparing result at equal time steps, filled percentage of die at the die temperature of $250^{\circ} \mathrm{C}$ is more than that of $150^{\circ} \mathrm{C}$.
Figures 11 and 12 show the results of solidification simulation. In this figure, it is seen that the peripheral area of the part is at the liquid phase while other areas are solidified. Therefore, these areas are susceptible to formation of shrinkage porosities. In order to reduce the cold flow 

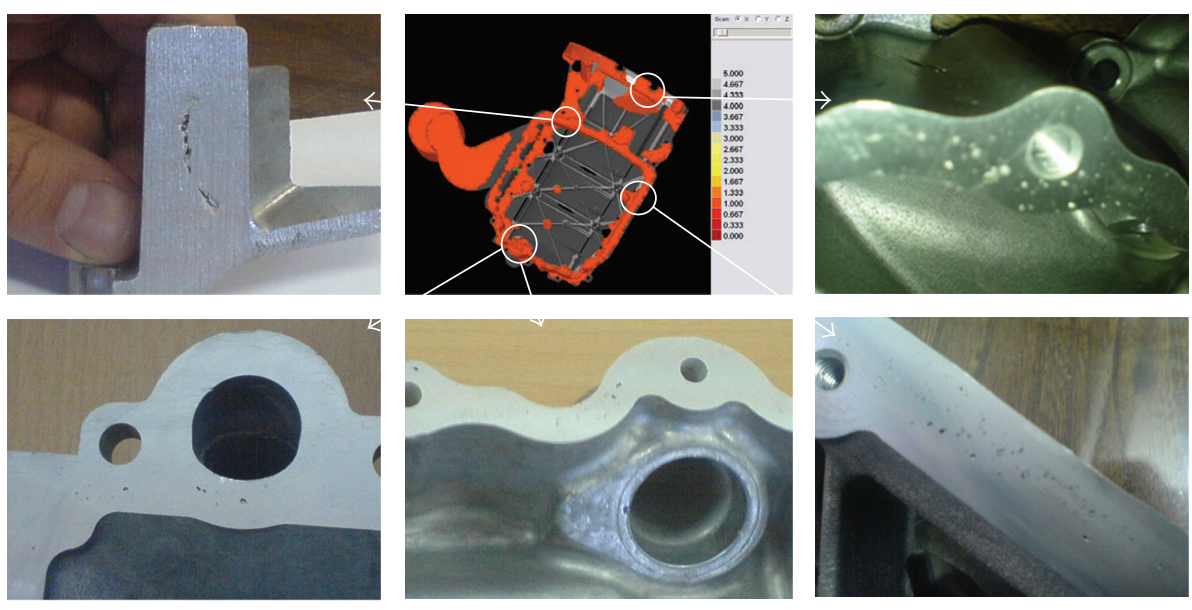

FIGURE 12: Defects occurred in final solidification positions.

defects and air porosities, overflows can be placed near these areas in the die design.

\section{Conclusions}

(i) Comparison of the experimental and simulation results indicates that defects in the pieces are placed at the predicted places by simulation.

(ii) Optimum die temperature for A380 alloy for H13 die material is around $200^{\circ} \mathrm{C}$.

(iii) If the die temperature is reduced from the optimum temperature range, probability of cold flow defects and air porosities increase.

(iv) Determination of optimized places of overflows by simulation led to decrease of some casting defects such as cold shots and air porosities.

\section{References}

[1] M. S. Dargusch, G. Dour, N. Schauer, C. M. Dinnis, and G. Savage, "The influence of pressure during solidification of high pressure die cast aluminium telecommunications components," Journal of Materials Processing Technology, vol. 180, no. 1-3, pp. 37-43, 2006.

[2] Z. W. Chen and M. Z. Jahedi, "Die erosion and its effect on soldering formation in high pressure die casting of aluminium alloys," Materials and Design, vol. 20, no. 6, pp. 303-309, 1999.

[3] P. W. Cleary, J. Ha, M. Prakash, and T. Nguyen, "3D SPH flow predictions and validation for high pressure die casting of automotive components," Applied Mathematical Modelling, vol. 30, no. 11, pp. 1406-1427, 2006.

[4] K. J. Laws, B. Gun, and M. Ferry, "Effect of die-casting parameters on the production of high quality bulk metallic glass samples," Materials Science and Engineering A, vol. 425, no. 1-2, pp. 114-120, 2006.

[5] D. McBride, T. N. Croft, and M. Cross, "A coupled finite volume method for the computational modelling of mould filling in very complex geometries," Computers \& Fluids, vol. 37, no. 2, pp. 170-180, 2008.
[6] C. C. Tai and J. C. Lin, "The optimal position for the injection gate of a die-casting die," Journal of Materials Processing Technology, vol. 86, no. 1-3, pp. 87-100, 1998.

[7] S. W. Youn, C. G. Kang, and P. K. Seo, "Thermal fluid/solidification analysis of automobile part by horizontal squeeze casting process and experimental evaluation," Journal of Materials Processing Technology, vol. 146, no. 3, pp. 294-302, 2004.

[8] J. X. Zhou, L. L. Chen, D. M. Liao, and R. X. Liu, "High pressure diecasting module of InteCAST software and its applications," Journal of Materials Processing Technology, vol. 192-193, pp. 249-254, 2007.

[9] S. Yue, G. Wang, F. Yin, Y. Wang, and J. Yang, "Application of an integrated CAD/CAE/CAM system for die casting dies," Journal of Materials Processing Technology, vol. 139, no. 1-3, pp. 465-468, 2003.

[10] A. Kermanpur, S. Mahmoudi, and A. Hajipour, "Numerical simulation of metal flow and solidification in the multicavity casting moulds of automotive components," Journal of Materials Processing Technology, vol. 206, no. 1-3, pp. 62-68, 2008.

[11] S. Schneiderbauer, S. Pirker, C. Chimani, and R. Kretz, "Studies on flow characteristics at high-pressure die-casting," in Proceedings of the 3rd International Conference on Advances in Solidification Processes.

[12] M. F. V. T. Pereira, M. Williams, and W. B. du Preez, "Reducing non value adding aluminium alloy in production of parts through high pressure die casting," in Proceedings of the Light Metals Conference, 2010.

[13] J. K. Rai, A. M. Lajimi, and P. Xirouchakis, "An intelligent system for predicting HPDC process variables in interactive environment," Journal of Materials Processing Technology, vol. 203, no. 1-3, pp. 72-79, 2008.

[14] B. S. Sung and I. S. Kim, "The molding analysis of automobile parts using the die-casting system," Journal of Materials Processing Technology, vol. 201, pp. 635-639, 2008.

[15] V. Ilotte, "Die casting for chassis components," in Proceedings of the 4th International High Tech Die Casting Conference, Montichiari, Italy, April 2008.

[16] Z. Brown, C. Barnes, J. Bigelow, and U. S. Contech, "Squeeze cast automotive applications and design considerations," in Proceedings of the 4th International High Tech Die Casting Conference, Montichiari, Italy, April 2008. 
[17] J. P. Papai, Contact heat transfer coefficients in aluminum alloy die casting: an experimental and numerical investigation? [Ph.D. thesis], The Ohio State University, 1994. 

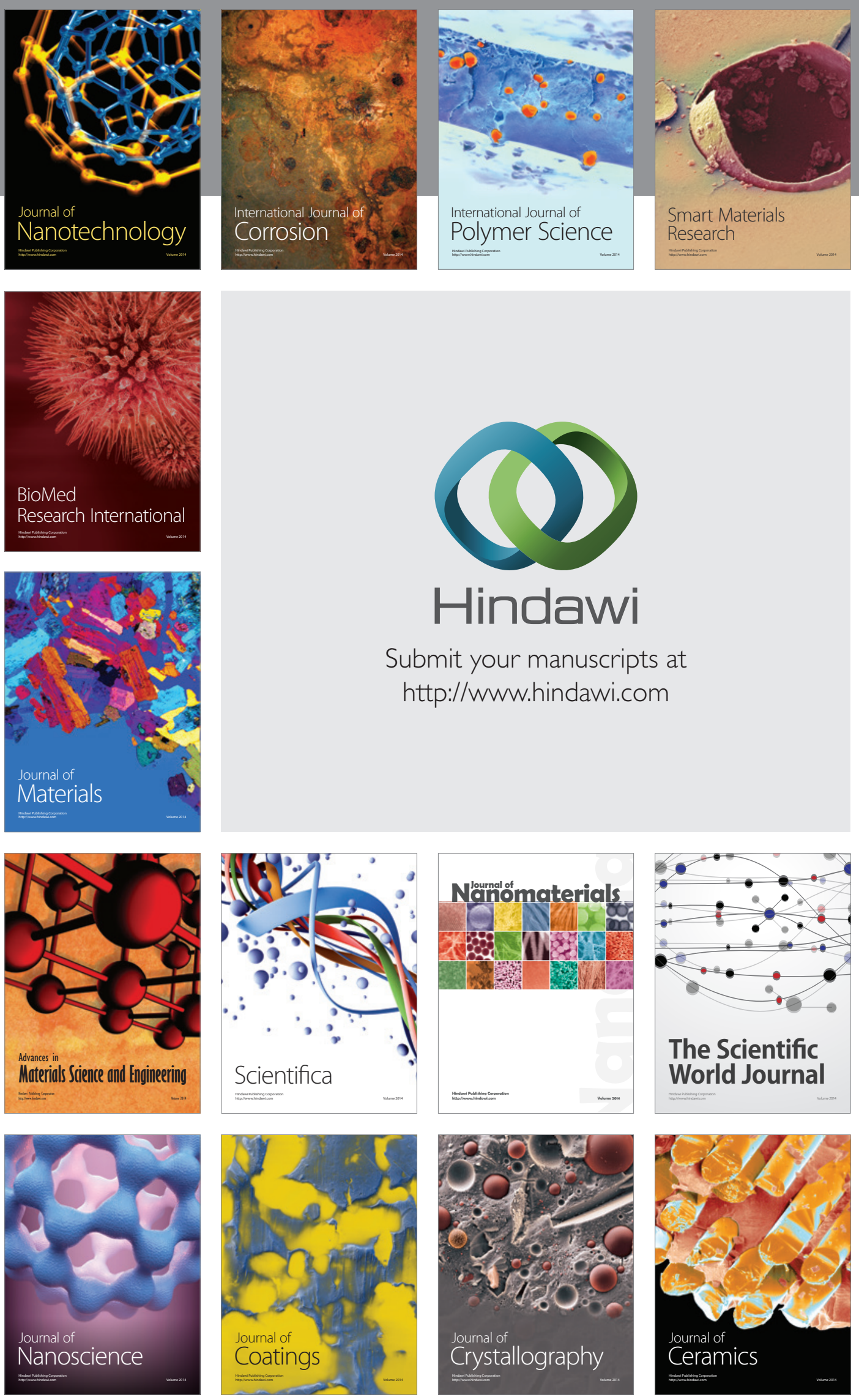

The Scientific World Journal

Submit your manuscripts at

http://www.hindawi.com

\section{World Journal}

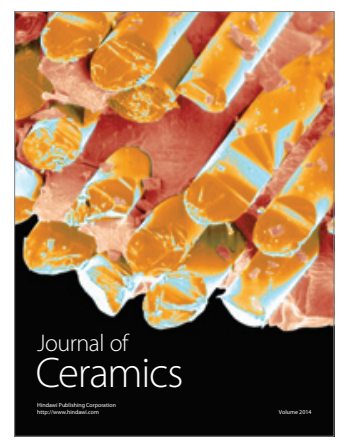

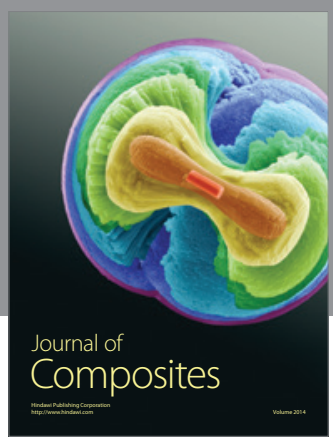
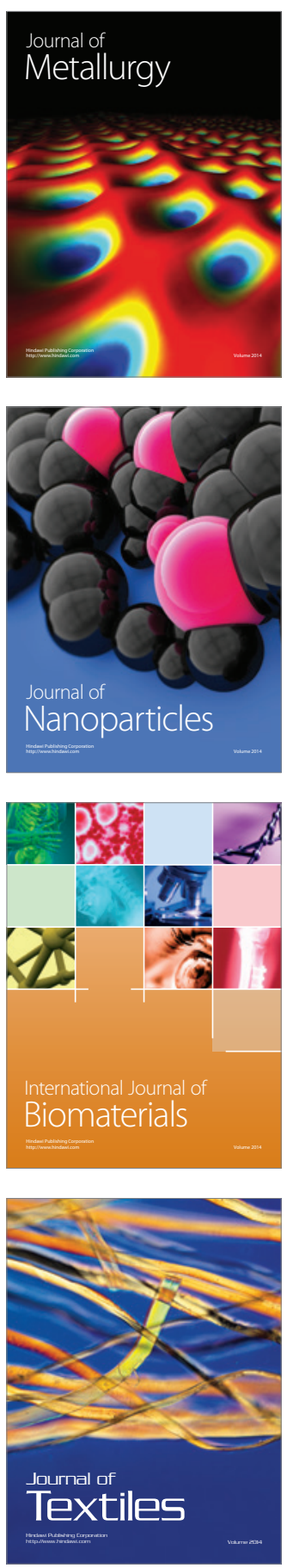